\title{
Relatedness, co-inquiring and imagination: mimetic images of recovery
}

\begin{tabular}{|r|l|}
\hline Journal: & Society and Business Review \\
\hline Manuscript ID & SBR-01-2017-0004.R2 \\
\hline Manuscript Type: & Research Paper \\
\hline Keywords: & Relatedness, Mimesis, Crisis, Co-inquiry, Emotions \\
\hline \multicolumn{2}{|}{} \\
\hline
\end{tabular}

\section{SCHOLARONE"}

Manuscripts 


\section{Introduction}

In this paper we analyse the ways that final year undergraduate students in a business school engaged with a co-inquiry into the meaning of recovery and change for businesses. The paper discusses in particular how co-inquiry helped students to imagine recovery and change through replica and mimesis. Our approach to coinquiry was a form of 'Inquiry Based Learning' (IBL), where students co-produced and 'read' text and visually based materials making their own decisions of what and how to inquiry about a topic. Indeed, IBL is based on the assumption that critical thinking is developed by maximising the capacity of students for learning driven by curiosity and ability to frame inquiry questions within a community of co-inquiry, (Author 2 and Author 1, 2012). We developed this approach over a period of three consecutive years, in each of which the focus of co-inquiry was linked to the theme and call for papers for the Standing Conference of Organisational Symbolism (SCOS), where findings were presented (SCOS, 2009, 'The Bridge'; SCOS, 2010, 'Vision'; SCOS, 2011, 'Recovery'). This paper presents a case study of co-inquiry in 2011 when we invited students to link their inquiry to the SCOS conference theme of Recovery. We draw from the pedagogical approach developed during these three years of co-inquiry, focusing in particular on the analysis of students' visual presentations. We analyse a) students' learning trajectories about change, in terms of business recovery, in the context of a formalized and institutionalized university module, b) our own learning experiences of working as researchers and lecturers in these circumstances and the tensions we experienced in bringing our critical reflections on business models of change and recovery into our interactions with the students and the institution, and c) our final reflections on the limits and learning 
value of the entire experience and how students engaged with co-inquiry, during the post 2007 crisis (Author 2 and Author 1, 2012).

In the case study presented in this paper we analyse the qualities of relatedness that developed between academic tutors and students engaged in co-inquiry in the context of the business school, and how multiple anxieties arose while engaging in deep learning. Furthermore the opportunity for us to co-author years after our experience of co-teaching and co-inquiry with students allows us to reflect anew on the quality of the affective link between us, developed in the context of co-inquiry, and the potential rewards of working through anxieties generated by pursuing a pedagogical approach that was countercultural (Perriton and Reynolds, 2004) to the solution focussed approach to learning familiar to the students in the business school (Author 1 et al, 2017; Grey, 2004). This paper endeavours to convey and to reflect on something of the qualities of the relatedness that developed between ourselves and with the students: curiosity, deep reflection, and resistance to solution focussed approaches to change management, which so many student textbooks encourage business students to adopt (Jones et al, 2005; Ladkin, 2006).

In the paper we draw attention to the ways that students selected texts and images, the content of their selections, and how their decisions were negotiated in inquiry groups and discussed with other students and academics. Our invitation to students was to engage with us in a prospective viewing exercise: to co-imagine a future state of recovery from crisis (in particular post 2007) and to construct a visual and nonvisual narrative to explore the inter-relationship between crisis, recovery and change. This invitation was not to discuss recovery as opposed to or as a condition of change. Rather, our interest was in whether or not it was possible for students and academics to imagine and to project a management discourse of the future, in the 
context of their current co-inquiry experience in a business school. The invitation was based on the supposition that future managers commonly use prospective discourses (Ybema, 2004a, 2004b).

An unexpected finding emerged during this process: co-inquiry helped students to imagine recovery and change through replica and mimesis. We will show how this was linked to the qualities of relatedness established between academics and students in the context of co-inquiry, in the overall economic and political context.

This paper explores these possibilities (1) by presenting the case study, defining the theoretical framework and justifying the methodological approach; (2) through a content analysis of data from three main sources which emerged from our work with the students - inquiry questions, visual images and concepts of recovery; and (3) by reflecting on the implications of how students produced their visual materials, by copying, through the lens of the concepts of replica, mimesis and postcolonialism.

\section{The case study}

Managing Change was a third-year undergraduate module in the business school of a post 1992 British university attended by a multi-ethnic cohort of students with a majority of British (40\%), South Asian (20\%), East Asian (20) and other cultural (10\%, mostly European) backgrounds. The pedagogical approach of the module was based on Inquiry Based Learning, a student-centred methodology by which students learn through a process of questioning, rather than solution finding, and learn to critically engage with constructs embedded in their experience, in current media reports and in academic texts (Author 2, Author 1 and xxx, 2008). At the beginning of the module, students were asked to formulate for their first assignment three inquiry questions about recovery and change, as a basis for their learning throughout 
the module. They were required to make links between their questions and key readings on change management, which were introduced by academics in lectures and tutorials. A second assignment consisted of an assessed research presentation in which the students, organised into groups, were encouraged to analyse the use of visual narratives of recovery and change in a chosen current business context. For their group presentations they were free to use drawings, photographs, collage, or any method of producing or selecting images. The third assignment was an essay in which students were asked to analyse a chosen visual narrative and its constructs for promoting organisational and business recovery and change, supporting their arguments with an appropriate discussion of the literature introduced in lectures and tutorials. Following Rose (2008) we introduced visual inquiry as a way of interrogating how to construct and to interpret visual material. Students learned through this how to construct meaning through making visual presentations, and how to critically analyse and interpret visual materials representing recovery and change (Author 2 and Author 1, 2012).

\section{Pedagogic approach: inquiring with students on recovering and change}

Co-inquiry was conducted within the constraints of a weekly timetabled lecture and seminar. Lectures, seminars and assignments were designed to stimulate critical inquiry into the assumptions and values embedded in change management theory (Author 2, Author 1 and $\mathrm{xxxx}, 2008$ ). At the beginning of the module, this approach met with considerable challenge from students. This was vocalised in the form of questioning what asking questions had to do with learning? How was student experience of change relevant as a resource for learning about change in business contexts? In assignments, students showed a preference for models of change management process, and solution based change management tool kits. As tutors and 
co-inquirers, we spent a great deal of time processing and responding to student challenge and discussing how to accredit their learning through inquiry. Student anxiety about assessment performance was high, as this was their final year. Modelling co-inquiry by embodied curiosity and dialogue, in our interactions with each other and with students, proved to be an important means of encouraging students to engage with co-inquiry. Results were evident in the change in our relatedness to the students, as the year progressed. Indeed we found that after the module was completed, and students had graduated, many renewed contact on a casual and spontaneous basis, greeting us in chance encounters outside the university and telling us how they had enjoyed and found value in their learning work on the module.

During first-term lectures and tutorials we introduced a range of conceptual frames to support critical analysis of how change management and leadership in business contexts has been conceptualised. These included organisational metaphors such as 'time and change', 'change as drama and performance - 'heroes and villains', and such questions as 'Who are the actors and agents of change?' 'Can change be led from the margins'? 'Leading diversity and equality change' and 'Is sustainability possible in business contexts?' Our tutorials were designed to encourage students to identify the value base embedded in change management theory, and to investigate how this might sit with the values they might bring to a management or leadership role (Author 1, 2012; Author 2 and Author 1, 2012). These were supported by visiting speakers, including former students, who addressed ethical dilemmas they had experienced in their management roles in banking, public services and industry. In weekly seminars, we encouraged students to develop their understanding of the complex systemic interlinking between businesses, government and civil society and to critique recipe-based and solution-focussed approaches to recovery from crisis. 
Our emphasis was on the global scale and systemic nature of the crisis (Gills, 2010; Leiser, Bourgeois-Gironde and Benita, 2010) and the values base of problematics of recovery. We met regularly to plan each cycle of seminars, to discuss student interactions and inquiry process within seminars we had each facilitated, to devise ways of taking the co- inquiry forward, and to discuss our own responses and experience of engagement with students. A critical factor was the anxiety evoked in ourselves by tensions between the instrumental approach to learning adopted by students, and encouraged in much of the business school culture, and the experiential and collaborative approach to learning that we sought to encourage through coinquiry. As the module progressed, and students saw that the assessment criteria supported co-inquiry, many students referred to their enjoyment of a more independent and student led approach to learning than they had experienced on other modules (Author 2 and author 1, and xxx 2008).

In joint reflections on these discussions with students and observation of how groups of students approached their assignments, we came to the conclusion that student presentations were constructed through mimetic representations. The presentations seemed to be what, in some visual methodologies, are considered evidence of the social (Knowles and Sweetman, 2004). They appeared to be a means to an end for understanding how recovery is socially constructed in the process of "creating meaning, drawing elements from an overabundant reality" (Boje and Baskin, 2011, p. 415). In the analysis that follows we demonstrate that students' preference was to copy, re-interpret and re-present found images and texts which they linked to recovery or change, in order to make a sort of replica which helped them, through a process of creating similar images and texts, to explain to others and to themselves what recovery and change could mean. 


\section{Theoretical approach: mimesis, similarity and replicas}

Mimesis can have an impact on practice in a variety of ways. It may, for instance, serve to manage the unknown. It has been suggested that making replicas of the real, particularly the social, and then (rhetorically) managing the replicas (because the real is unmanageable), is an established practice in the modern and contemporary world (Boltanski and Thévenot, 1991). Furthermore, mimesis, as a practice of creating the similar, in particular as a representation of the material and the social world, has been discussed since Plato, extensively theorised (Melberg, 1995) and analysed in literary studies (Auerbach, 1953), art and culture (Benjamin, 1933; Adorno, 1984, [1970]; Gebauer, Wulf and Reneau 1996); and particularly in sociology (Tarde, 1890) and anthropology (Taussig, 1993).

Tarde's development of the concepts of social duplication and replicas has been the inspiration for such seminal philosophical discussions and theoretical developments as Deleuze's thesis on repetition (1968) and Latour's ANT theory (2011). Organisation studies scholars appear to have found inspiration in Tarde's concept of knowledge diffusion by replication. DiMaggio and Powell's (1983) explanation of the inability of leaders to understand organisational crisis or to solve the problems associated with it using replication rather than innovative practices, resonates in Tarde's explanation of the way innovation is spread: by a mimetic process of imitation, in which the greater the similarity between an innovation and current work, the greater the probability that innovation will be adopted (Kinnunem, 1996). According to DiMaggio and Powell (ibid), organisational actions in times of crisis are based on the behaviour of leaders, who often decide on mimeting organisational events that are considered to have been successful in the past. 
Taussig's work on mimesis seems to have had an impact on discussions about management creativity and innovation. Taussig's concepts of 'repetition' and 'habitual appropriation' were the basis of justification of Slutskaya's concept of 'unimaginative creation' (2006) and Parker and Cooper's (1998) analysis of the power of the copy to create the original in cyber-organisational representations, for example. The main rationale for considering Taussig's perspective of the mimetic construction of organisational objects is what Hardy et. al (1998) have suggested to be 'synergistic creativity', a reciprocal creation of the original and the copy. Postcolonial literature has also emphasized the role of replication in imagining organising, in particular its visual manifestations (Punter, 2000), the relation between past and future events (Roque, 2005) and the role of mimetic constructions when foreign texts and visual narratives are appropriated and used in local media (Bohme, 2017).

\section{Methodology and analysis}

The approach we adopted for our analysis of student co-inquiry process followed the principle of 'sensory ethnology'. Sensory ethnology is rooted in ethnography and considers it appropriate for the ethnographer to be part of the social field of inquiry, and for the field to include visual and all aspects of the sensory in lived experience (Pink, 2009). In our role as tutor researchers we each took field notes from the seminar groups we led and discussed these at our planning meetings between seminars. In our field notes we referred to our experience of doing inquiry with the students, including differences in perception and understanding of recovery and of change, and how these were expressed and negotiated in the classroom. The notion of mimesis as a conceptual framework for understanding the student approach to their presentations, their constructs of the visual, emerged in our analysis of student 
inquiry process, as a way of making sense of our observations of how students approached their assessed presentations. Students were asked to put together a group visual presentation and commentary on constructs of success and of recovery created by a business organisation of their choice. We observed how students selected and used visual materials created by business organisations, their interpretation of the constructs produced by these materials, and their critical reflections on the value base of these visual constructs and images of business recovery. We found that students put their presentations together by selecting found images from internet sites, juxtaposing and combining images that appeared to be disconnected, and in this way composed presentations with their own narrative and meaning. It seemed to us that the visual presentations had become texts that the students were co creating.

Indeed, writers on visual research methodology in organisation studies are concerned with methods of generating and interpreting visual data (Rose, 2008; Warren, 2002). The visual materials that students created and used were in this sense what Rose (2008) refers as visualities, a term for images as texts. This concept of images as representations of the social and, as such, a form of text, was first proposed within semiology. Barthes' (1977) concept of textualisation as a social practice suggests that any type of representation - image, text, music - can produce and reproduce reality through a discourse.

We focussed our analysis on three main areas. What type of questions on recovery and change did the students bring to their learning at the beginning of the module? Which images did the students use to illustrate recovery and change (original, copies) and how did they use (re-use) them to illustrate their stories? And finally, which concepts and literature did they prefer to use to support their visual and nonvisual arguments? We based our analysis on a sample of assignments relevant to 
these areas, choosing the first, in which students identified the inquiry questions on recovery and change that they wished to investigate on the module, and the third, in which they presented and analysed visual material. Our sample consisted of all the presentations produced during assignment 2, and 25 assignments (70,084 words, 156 images) from the third assignment, including the five assignments awarded the highest grades. Our analysis was informed by our field notes and pictures of interactions between the students as they presented, and additional notes and commentaries we produced during our marking, moderation and informal discussions with students.

\section{Questions on recovery and change}

Students were asked, for their first assignment, to identify three questions they had brought to the programme that would provide them with a focus for their learning and inquiry about recovery and change. In tutorials we invited students to share their experiences of change in organisational contexts, including the university, and to reflect on what they could learn from these discussions about change and recovery process. Most students had experience on work placements, in which they had been responsible for implementing an organisational change, on a small scale. We were surprised to find that despite encouragement in tutorials to investigate their own experiences of change and of recovery, in their written assignments more than $90 \%$ of students appeared to consider change and recovery to be something external to themselves, not something that it was possible for them to initiate or to direct. A significant minority did refer to themselves as subjects of change initiated by others, and showed a desire to reflect in their assignments on how they experienced their own change processes. Some students focused on existential concerns about whether 
new learning and knowledge acquired through their studies would change them in any way.

Many of the students approached inquiry by reflecting on how past events connected to the present, rather than on how events of the present might connect to a possible future. We decided to address this by inviting students to approach crisis, recovery and change through a collective exploration of an imaginary future. To stimulate this inquiry we invited students to watch a film clip of an imaginary future world Avatar (Cameron, 2010). We asked them to discuss how the value base of its 'alternative world' might relate to their own and what similarities or differences there might be to the values embedded in current business recovery and change initiatives. This proved to be a step too far for students, who rejected our invitation as having little relevance to their concerns. They did however express anxiety about how the past and present could enable their future prospects. We concluded that their concerns and sense of being objects of change, not subjects, outweighed their capacity or motivation to engage in imagining a collective future. Our response to student rejection was to conclude that we had chosen the wrong film clip-, would Metropolis (Lang, 1927) have been preferable? Had we presented a choice that seemed naïve, insufficiently serious- in the eyes of student in a business school?

There was consistency in student accounts of their experience of managers or leaders, either as obstacles to or as promoters of recovery and change by facilitating, finding solutions or innovating. In their accounts of when a manager became a barrier, their subsequent questions were focussed on finding past solutions for 'overcoming' that barrier, rather than on interrogating the construct or meaning of recovery of change. Similarly, many questions focussed on how to overcome 'resistance' to change by finding inspirational examples from the past. 
Change was constructed as something resisted and initiated by others; students seemed to take it at face value, as an inevitable fact of life. In this sense, students at this point in the programme (the beginning of their final year at university) constructed themselves as passive subjects or objects of change. While they referred to experiences of change that may have been painful or challenging in their personal lives, they did not consider that change in organisational contexts could be a problematic challenge for them. As future managers, they were expecting to learn how to apply recipes to manage others as potential barriers to change.

Images of recovery and change

Students organised themselves into self-selected groups to analyse the use of images to represent and to promote change or recovery in organisational contexts. Groups were asked to choose an organisation where change was being promoted as part of a business recovery, to develop an analysis in their tutorial group, and to put together a visual presentation of their work, as part of their assessed coursework. The assignment was a popular one; students appeared to enjoy the opportunity for selfdirected group research and to have academics as moderators. The task required inquiry ability, a capacity for group negotiation, and visual and verbal presentation skills.

Students selected organisational and non-organisational situations from well known contemporary examples, with images from the Internet - situations that they were not involved with, situations which could be illustrative of what to do, rather than organisations or people with which they were involved. The most popular examples were Apple, McDonald's and General Motors. 
Pictures were usually located at the beginning of the presentations. Students did not modify the pictures, but used juxtapositions and composition to create digital collages comprising images copied and pasted from the Internet. These images were used as evidence in their presentations of their inquiry findings and to illustrate their analysis of business use of visual images to represent recovery or change.

McDonald's images were commonly used to exemplify the company's strong association with the unhealthy, a status from which (according to the students) the company had started to recover. Collages with McDonald's pictures were exposed symmetrically, usually in a square disposition, mixing McDonald's logos with modified pictures used in blogs and social forums (a triple Mega Mac with six hamburgers, and Ronald McDonald as an unhappy clown). During their presentation, the students explained the pictures one by one, and made linkages with arrows and lines to justify how the images served to explain the change. McDonald's reputation for unhealthy food was thereby juxtaposed with the unhealthy state of the company following the Dasani scandal.

Another common use of images was to show how the visual is used in the media - or in such independent media as street art - to represent or subvert business images of recovery. In this situation, the students assumed the role of presenters not only of images used for other purposes, but also of explanations about the images by others: the press or the marketing campaigners or a social movement. Images from Apple were used to create a poster around Steve Jobs dressed as a medical doctor and trying to 'recover' a patient from a cardiac attack. In the poster, graphs of the evolution of Apple shares copied from a business newspaper were displayed in one corner. The entire poster was a collage of images, and it was the graphs that were intended to provide clarification. The students' presentation was limited to explaining the 
evolution of the shares before and after Steve Jobs took over the company and after he died. In another case, a single poster was made with images of an organisation to which the students belonged: the very university where they were studying. Change and crisis was explained to us through a collage of 30 images, only 6 of which were from the university web site; 24 were from other web sources. This sequence, which re-created the university's image with pictures of buildings and logos, was used to suggest a series of changes in direction taken by the university. Crisis, using in particular images inspired post 2007, was presented to the audience by using images of Big Ben lying on its side, fallen, and a Teddy Bear with caricatures of Gordon Brown and David Cameron, prime ministers in Great Britain, and a montage of students demanding a fee reduction.

It was noticeable that although they had been encouraged to share and base their inquiry on their experiences of change in the workplace, none of the students chose cases that were directly connected to their experience as employees. Nevertheless in their analyses of how visuality was used by these organisations as a dimension of their change and recovery process, it often seemed that students did feel closely connected to the brand of the organisation they had researched.

\section{Concepts and models used of recovery and change}

For their third assignment, students wrote an individual essay based on their group research and presentations. In this section we offer a content analysis drawn from five of these student essays. We have selected these to illustrate the concepts of recovery and change used by students to support their analyses of the use of visual images and how they engaged with the ethics of recovery and change. 
The first assignment chose to analyse recovery of one of the political parties in the Coalition Government of Great Britain. The analysis focussed on how the party represented change in its values and practices, through visual images, and analysed media representations of these values and practices. The values promoted were associated with a rebranding of the party away from conservative associations with a narrowly defined traditional family life, focusing instead on the leader as a modern, caring family man associated with green politics, with a capacity to take the necessary steps to reduce the national debt, while retaining commitment to public services. Visual images were also used in attempts to discredit the leader of the opposition, through manipulation of party campaign posters. The student found that visual representations played a key role in this attempt to rebrand the party, to recover from negative associations and to project an image of changed internal values and practices in campaigns to increase party support. They were a powerful communication tool for reinforcing positive associations with the party and negative associations with the party in power. In this sense they were a key to recovery and change.

Another essay focussed on Coca Cola and Marks and Spencer, both of which were said to require ethical change. The essay referred to presentations where students had each chosen images that symbolized scandals in these organisations, and visual images that represented recovery from those experiences. In this essay following an approach we had introduced in lectures (Ladkin, 2006; Jones et al., 2005) the student defined ethical change as a way of self reflecting rather than a mindless following of rules. In contrast, student presentations had found that these companies' recoveries were limited to opportunist responses of organisations, rather than an elaboration of ethical values of their own. The purpose of their recovery, she concluded following Carnall (2007), was to be seen to be winning over competitors through a capacity for 
faster response to change, and, in this context, to respond by positioning themselves as helping to save the nation from ill health, while keeping customers interested in the brand. Visual images promoting the new Coca Cola bottle, were used in promotions to help recover from the scandal of Dasani (Coca-Cola's brand of bottled water which was, alleged to be tap water that had undergone reverse osmosis and the addition of trace minerals). Recovery was distinguished from change and change was considered inevitable, independent from any previous action, a sort of fatal destiny; yet similar to managing change. Students' testimonies were similar in the idea of manipulating, making change happen, following Northcote (2008) in order to turn out things in the way they intend.

In a third essay, Kurt Lewin's (1946) model of change was contrasted with a continuous state of change (Burnes 2004), within an analysis of Woolworth's attempted recovery. It was stated that images played a key role in defining Woolworth's as an online store, as without the images the organisation would not have been perceived to be successful. Time, in particular the idea of the extreme peremptory demands of the market, was introduced as a dimension of change and historical rhetoric as a disabler, impeding the organisation from necessary transformation.

In a fourth essay, the student analysed Apple's use of visual images to achieve recovery and change. Here Apple was described as using visual images to represent the way they wanted to be viewed, with a focus on everyday practices and values. Visual images were intended to convey the core message of their mission statement: to redefine the future of mobile media and computing devices, and to create a credible image of a successful company that had recovered from failure. In heroic images of Steve Jobs, the CEO was associated with these changes. In this essay, as in 
the first, Gillian Rose's (2008) three sites of meaning were used to support the argument that the visual images employed by organisations to promote a narrative provide a medium for connecting with stakeholders who will create their own stories and visions of organisations.

The final essay in this sample analysed Skoda's recovery - a transformation of image and self image -following the takeover by Volkswagen. The analysis was conducted through a visual reading of the narrative evoked by their changing logos. As in the first essay, images were seen as powerful but unreliable, as they are open to different interpretations. This ambiguity was perceived to be both an asset to business recovery and a source of vulnerability.

\section{Reflections}

Students enquired into organisational dilemmas concerning crisis, recovery and change, textualising through images that had been produced by organisations, institutions and artists, most of them through web pages published by news agencies and formal and informal internet forums (Author 2 and Author 1, 2012). They claimed that new inquiry questions on these issues emerged not from the images alone, but from the thoughts they brought to the images and from discussion of the images in the context of their interaction at tutorials and seminars. In summary, when students were given the opportunity to reflect and visualise on the themes of crisis, recovery and change, they used images produced by others.

Our research has led us to question why students copied and pasted images, mainly from the Internet, to create a visual presentation, and why they seldom used images from their own organisational worlds when inquiring on crisis, recovery and change. Could it be that they were experiencing the need to escape from university and their 
programme of study? Or the fact that they would soon be leaving the university, the cost - cutting culture and the high unemployment among university graduates? It is our intention to reflect on why in situations of crisis, mimetic practices emerge as way of representing change.

Following Said's suggestion of how this copying process operates (1979), it seems to us that resemblances, similarities, copies, replicas, and illustrative selections of generally American firms enabled the students to imagine the future. Indeed, American firms, in particular those with extended presence in the media, are usually considered in business schools to be paradigmatic models of business success and are used sometimes as totemic artefacts, universal examples of business practices. Students did this not through metaphorical representations, but by engaging with these replicas as part of a social practice, because they considered the replicas to be similar to future practices and dilemmas, which they could illustrate. In this sense, images of crisis, recovery and change (not merely metaphors) illustrated concepts, or vice versa, through the use of copied and pasted images from other contexts and rationales used for other purposes.

It could be argued that students were merely lazy, and that they found it easier to copy than to create. This was indeed the response consistent with the assessment culture, with its tendency to view copying as plagiarism. To interpret their work in this way, however, would be to ignore the time and effort involved in the selection and composition of the visual content and the quality of the electronic posters. The mimetic approach taken by the students was not a function of the way the assignments had been set up, as the students were given freedom to decide how to create the posters and were encouraged to use their own materials. 
Because of our relatedness with the students, in the context of learning through coinquiry, we were inclined more towards the possibility that this process was illustrative of a form of learning. Students were not merely copying, but engaging in a creative process of composition and interpretation, in which the raw materials were found images that were selected, copied and pasted into their presentations. Our interpretation of this process is that by acquiring knowledge about managing the mimetic object, students might more easily return to the real; management of the original may be experienced as more possible, thanks to knowledge acquired in managing the copy-paste posters. This way of knowing may be better understood from the point of view of what Simpson has called 'touch reality' (Simpson 2010, 175), a capacity to 'see' reality without the filters of language. We argue that the mimetic object provoked in the students the fantasy that the replica was fully 'touchable' and knowledgeable, and, through it, so was the original.

In a story, events associated with crisis, recovery and change happen at another time than the present or the future. We talk about, write or imagine our present experiences, but we explain the crisis, the change or the recovery as not happening at the same time as we are narrating them. Following Luhmann '[if] a system had to react to the environmental events that befall it the minute they happen, it would have little chance to select its mode of reacting' (Luhmann 1995, 186, quoted in Czarniawska 2004, 777).

We found that students created their stories by associating images and texts that had been created in the past, not by trying to re-imagine them in the present moment, which is, following Luhmann, impossible. By doing this, the students seemed to be preparing for change and to be reflecting on recovery in a mimetic way. It was as if the assignments became a 'replica' they made available in order to practice and to 
reflect on the way organisations may respond to the post 2007 crisis, recovery and change in the future or had responded in the past.

Two main general conclusions may be drawn from this research. (1) Images and texts used by the students were considered attractive, appropriate, useful and, in particular, helpful for constructing convincing arguments based on their own beliefs and opinions. The students considered that those images and concepts, as proper mimetic objects, would also inspire their audience (tutors and other students) to arrive at similar conclusions. (2) Despite the fact that the module was founded on critical theoretical approaches to the ethical dimensions of crisis, recovery and change in particular (i.e. Ladkin 2006), students seemed to have no problem in combining these elements with solution-focussed business change models, in which ethical dimensions are unproblematised.

The are three further specific conclusions:

(1) Although encouraged to do so, it is apparent that students did not choose to critically reflect on what 'recovery' might have meant to them, in relation to their lived experience and value base. Instead they developed competent and insightful analyses of the use of visual images by businesses or political organisations to offer an illusion of transformation, by conveying a discourse of socially ethical business practices in response to consumer interest. Recovery was narrowly defined in business terms. There was little exploration of tensions between business success and wider social interest or inquiry into contested notions of recovery, and the implications for business.

(2) In tutorial presentations and discussions, we were surprised to note that many of our students seemed to have little sense of being in an 'economic crisis' or a shared 
sense of what we may need to recover from, collectively. This lack of connection with the world economy was despite considerable media debate about the post 2007 banking crisis and discussions that occurred in our tutorials and lectures, including at least one guest lecture from a banker. Student approaches seemed, with some exceptions, to be overwhelmingly individualistic - with little sense of collective responsibility, nothing about what it may mean to reduce or increase the role of the state as regulator or redistributor of resources or as provider of services. There was little engagement with the social role of business or with the question of how business could contribute to the elaboration of a vision of recovery from the economic crisis, and some irritation and challenge on grounds of the relevance of engaging in this type of discussion.

(3) Despite doubts about the relevance of engaging, there was, alongside initial scepticism, considerable sophistication in the students' discussions of the increasing use of the visual by business organisations, and of the relevance of learning how to read, interpret and make use of visual materials to convey complexity and to inquiry. Through their inquiry, students found that the visual was a means for businesses and organisations to transform themselves in the eyes of the consumer, and they were able to read them as narratives of the businesses' transformation and change. Their analyses were powerful and convincing, as if the power of organisations to transform perceptions of themselves were indeed a power to achieve and to embody transformation. Student assignments on visual narratives of change were persuasive of their own transformation into visual narrators, in which images and artefacts became evidence of values and practices, and were in themselves a means of achieving change. Yet alongside this persuasive narrative, the student voice remained sceptical, offering a commentary that reminded the reader that the students 
were fully aware that these simulacrae of ethical practice were nothing more than another form of innovation that made business sense.

\section{Concluding thoughts}

Where does this analysis take us in relation to our initial inquiry question: how did co-inquiry help students to imagine recovery and change through replica and mimesis? How was this linked to the qualities of relatedness established between academics and students in the context of co-inquiry, in the overall economic and political context?

Firstly, we found that students experienced considerable ambivalence in their authority and capacity to imagine recovery. Their reluctance to engage with our invitation to imagine a future recovery beyond a narrowly conceived notion of business success could be read as a defence against anxiety provoked by our invitation to introduce social values, to which they had expressed commitment earlier in their co inquiries, into discussion of what recovery might mean for business. Students in their third year, about to graduate, have little security or certainty to look forward to, and still less sense of themselves as business leaders. Consequently they may possess a lack of any confidence in their own capacity to make a difference, by acting on social values important to them, but that sit outside a predominant business paradigm. In contrast, their refusal could be read as a judicious assessment of what may be relevant to preparation to enter the business world- and to assessed work in a business school module, and a careful winnowing out of reflections on social and personal political beliefs because they believed such selfdisclosure to be risky. We do not presume to make interpretations of motive here or judgements about our students' moral sense, but simply to note our own surprise and 
sense of challenge from students to consensus that we believed we had reached, that we were sharing an experience of social crisis from which recovery was needed, and discovery from our students that this was not, after all, a point of view to which students were prepared to commit. The challenge was after all evidence that students had taken their own authority as learners to refuse to commit to tutor perspectives on recovery and change- and instead to assert their own.

Secondly, we found that our own experiences of introducing and sustaining an inquiry based approach in a context where it was countercultural proved to be both challenging and extremely rewarding. While we each experienced anxiety and tension when engaging with the co-inquiry process with students, our own parallel co-inquiry enabled us to sustain our inquiry stance with students, to learn from each other, and continue to build on and develop what we discussed and elaborated during the module. Indeed, there are alumni who make contact with us from time to time on email, or in chance encounters outside university premises, making reference to their experience of learning and how they continue to find it to be of value. As colleagues we still refer to times when teaching together was the experience which served as a basis for our friendship and a resource of creativity in our colleagueship. Interestingly, neither the students (now alumni) nor ourselves refer now in detail to the anxiety we experienced during our co-inquiry experience.

Thirdly, an epistemological and ideological suggestion for further research on the issue of "copying" emerged from this paper. To copy and paste is institutionalised as a forbidden practice. Academic institutions associate this practice with plagiarism. As Taussig has suggested, this stance creates a problem when something that may appear obvious for the institution is anything but obvious to researchers. Copies are always understood to constitute a sort of criminal practice as stealing something 
from another person. As such they are heavily sanctioned with expulsions, failing grades and disciplinary action, and are never considered part of the learning process. Yet, a great variety of postcolonial literature has suggested that copying as a way of making sense is indeed a common practice. In this paper we have argued that in complex organisations such as universities, replicating and mimetic practices are perceived and understood differently, by different actors, depending on how students and academics experience their relatedness, how they perceive and care for each other, and how they learn together. We suggest that co-inquiry, for students and tutors of business schools, provides a context in which these qualities of relatedness develop, and can be made explicit as dimensions that contribute to the learning and teaching process.

\section{References}

Adorno, T. (1984/1970). Aesthetic theory. London: Routledge.

Auerbach, E. (1953). Mimesis: The representation of reality in western literature. Princeton: Princeton University Press.

Author 1. (2012). The rhetoric of synergy in a global corporation: Visual and oral narratives of mimesis and similarity. Journal of Organizational Change Management 23, no. 2: 265-282.

Author 1, Simpson, P. and Cicmil, S. (2017). Re-imagining business schools of the future as places of theorizing. In: Izak, M., Kostera, M.and Zawadzki, M., eds. (2017) The future of university education. London: Palgrave. 
Author 2 and Author 1. (2012). A visual inquiry into ethics and change, Qualitative Research in Organizations and Management: An International Journal 7, no. 1: 7285.

Author 2, Author 1 and C. Jarvis. with E. Attwell, M. Lukaj, L. McCann, S. Hayward and L. Hindson. (2008). 'Student and lecturers' experiences of introducing a hybrid IBL approach to teaching organisation studies in a business school'. HEA academic papers on line: http://escalate.ac.uk/5265.

Barthes, R. (1977). Image, music, text. New York: Hill and Wang.

Benjamin, W. (1933). On the mimetic faculty. Walter Benjamin: Selected writings, Volume 2, 1927-1934. Ed. Michael W. Jennings, Howard Eiland, and Gary Smith (1999). Cambridge: Belknap of Harvard UP: 720-722.

Bohme, C. (2017). Matthias Krings, African Appropriations: cultural difference, mimesis, and media. Africa 87, no. 2: 434.

Boje, D. and K. Baskin. (2011). Our organizations were never disenchanted. Enchantment by design narratives vs enchantment by emergence. Journal of Organizational Change Management 24, no. 4: 411-426.

Boltanski, L. and L. Thévenot. (1991). De la justification. Les économies de la grandeur. Paris: Gallimard.

Burnes, B. (2004). Managing change: A strategic approach to organisational dynamics. Harlow: Pearson.

Cameron, J. (2010). Avatar. Fox. 
Carnall, C. (2007). Managing change in organizations. Harlow: FT-Prentice Hall.

Czarniawska, B. (2004). On time, space and action nets. Organization 11, no. 6: 773-779. London: Sage.

Deleuze, G. (1968/2004). Difference and repetition. London: Continuum.

DiMaggio, Paul J., and Walter W. Powell. (1983. The iron cage revisited: Institutional isomorphism and collective rationality in organizational fields. American Sociological Review 48, no. 2: 147-160.

Gebauer, G., Ch. Wulf and D. Reneau. (1996). Mimesis: Culture-art-society. London: University of California Press.

Gills, B. (2010). Going South: capitalist crisis, systemic crisis, civilisational crisis. Third World Quarterly 31, no. 2: 169-184.

Grey, C. (2004). Reinventing Business Schools: The Contribution of Critical Management Education. Academy of Management Learning \& Education, 3, no. 2: 178-186.

Hardy, C., N. Phillips and T. Lawrence. (1998). Distinguishing trust and power in interorganizational relations: Forms and façades of trust. In Trust within and between organizations, ed. C. Lane and R. Bachmann, 64-87. Oxford: Oxford University Press.

Jones, C., M. Parker and R. ten Bos. (2005). For business ethics: A critical approach. Oxon: Routledge. 
Knowles, C. and P. Sweetman. (2004). Picturing the social landscape: Visual methods and the sociological imagination. London: Routledge.

Ladkin, D. (2006). When deontology and utilitarianism aren't enough: How Heidegger's notion of "dwelling” might help organisational leaders resolve ethical issues. Journal of Business Ethics 65, no. 1: 1-18.

Lang, F. (1927). Metropolis [reconstructed and restored], Eureka.

Latour, B. (2011). Networks, societies, spheres: reflections of an Actor-Network theorist. International Journal of Communication 5: 796-810.

Lewin, K. (1946). Action research and minority problems. Journal of Social Issues 2, no. 4: 34-46.

Leiser, D., S. Bourgeois-Gironde and R. Benita. (2010). Human foibles or systemic failure - lay perceptions of the 2008-2009 financial crisis. Journal of SocioEconomics 39, no. 24: 132-141.

Luhmann, N. (1995). Social systems. Stanford, CA: Stanford University Press.

Melberg, A. (1995). Theories of mimesis. Cambridge: Cambridge University Press.

Northcote, E. (2008). Making change happen. London: JN.

Perriton, L. and Reynolds, M. (2004). Critical Management Education: From Pedagogy of Possibility to Pedagogy of Refusal? Management Learning 35, no. 1: $61-77$.

Pink, S. (2009). Doing sensory ethnography. London: Sage. 
Punter, D. (2000). Postcolonial imaginings: fictions of a new World order. Edinburgh: Edinburgh University Press.

Roque, R. (2015). Mimesis and Colonialism: Emerging Perspectives on a Shared History. History Compass, 13, no. 4: 201-211.

Rose, G. (2008). Visual methodologies: An introduction to the interpretation of visual materials. London: Sage.

Said, E. (1979). Orientalism. New York: Vintage.

Simpson, P. (2010). Engaging with the unknowable through narrative and personal experience. Journal of Organizational Change Management 23, no. 2: 173-179.

Slutskaya, N. (2006). Creativity and repetition. Creativity and Innovation Management 5, no. 2: 150-156.

Tarde, G. (1890/1903). The laws of imitation. New York: Holt.

Taussig, M. (1993). Mimesis and alterity: A particular history of the senses. London and New York: Routledge.

Warren, S. (2002). Show me how it feels to work here. Ephemera 2, no. 3: 224-245.

Ybema, S. (2004a). Managerial postalgia: projecting a golden future. Journal of Managerial Psychology 19, no. 8: 825-841.

Ybema, S. (2004b). Rhetorical strategies, temporal discourse and organizational change. $6^{\text {th }}$ International conference on Organizational Discourse: archetypes, archetexts and artifacts. Amsterdam: VU University. 